\title{
Vitreous Detachment
}

National Cancer Institute

\section{Source}

National Cancer Institute. Vitreous Detachment. NCI Thesaurus. Code C50807.

Detachment of the vitreous humor from the retina. 